Punishment \& Society

\title{
Women's voices made visible: Photovoice in visual criminology
}

\begin{tabular}{|c|l|}
\hline Journal: & Punishment \& Society \\
\hline Manuscript ID & PUN-16-0123.R1 \\
\hline Manuscript Type: & Normal Manuscript \\
\hline Keywords: & $\begin{array}{l}\text { women, photovoice, visual criminology, visual methods, participatory } \\
\text { photography, probation, Hungary, England, vulnerable populations }\end{array}$ \\
\hline Abstract: & $\begin{array}{l}\text { The voices of women subject to the criminal justice system are often } \\
\text { ignored and unheard. This article considers the effectiveness of photovoice, } \\
\text { a form of participatory photography research, as a visual method of } \\
\text { enabling and communicating marginalised women's experiences in } \\
\text { criminological research. By utilising the potentially empowering technique } \\
\text { of photovoice in two research projects, the narratives of women who inject } \\
\text { drugs in Hungary and women who have experienced supervision in England } \\
\text { are conveyed through their own participant-generated photographs. These } \\
\text { images convey the pains and aspirations of the participants' lives and show } \\
\text { how photovoice is a useful method for visual criminological research and } \\
\text { exposes the shared problems faced by two vulnerable populations across } \\
\text { two countries in Europe. }\end{array}$ \\
\hline
\end{tabular}




\section{Introduction}

2 Photovoice is an engaging qualitative method that has great promise for visual criminological

3 research. The photovoice method involves providing research participants with cameras to photograph

4 their experiences and understandings of the phenomena of study. Photovoice is a tool for facilitating

5 interactions between everyone involved in the research to produce meaningful and insightful material

6 via participatory photography. The discussions that emerge from the photographs privilege the

7 perspectives of research participants and those most intimately connected to the research topic. This

8 article discusses how photovoice can be used in criminological inquiry. The first section gives an

9 overview of the development of photovoice and the main principles involved in the visual method,

10 including analysis. The second section describes how images and photographs have historically been

11 used in criminology as a tool of social surveillance and control. The third section discusses the results

12 of different research projects with women in the criminal justice system that used photovoice as the

13 main form of data collection, conducted separately by the authors of this article. The final section

14 details a selection of common themes that emerged from both research projects, and is accompanied

15 by the relevant selection of photographic data for each theme. The article concludes with a brief

16 reflection on the potential of photovoice in criminological research.

\section{Photovoice: the photograph as a research tool}

18 Photovoice is a visual method that consists of the researcher providing cameras for

19 participants to take pictures, and then collaboratively discussing and analysing those pictures.

20 Different from conventional research involving photography, the photovoice method advocates that

21 participants rather than researchers document the issues of inquiry by taking photographs. Photovoice

22 is grounded in the larger research tradition known as Action Research or Participatory Action

23 Research, which broadly strives to increase knowledge and facilitate conscious-raising of the topic

24 and outcomes of research issues through democratic processes of involvement (Fals-Borda, and

25 Rahman, 1991; Friere, 1979; Kindon, Pain, and Kesby, 2007; Reason and Bradbury, 2001; Wang, 26 1999). 
27 Photovoice is a method of research inquiry that "uses the immediacy of the visual image to

28 furnish evidence and to promote an effective, participatory means of sharing expertise and

29 knowledge" (Wang and Burris, 1997: p. 369). It operates on the belief that images are powerful forms

30 of knowledge that have the potential to communicate information as well as depict individual and

31 community needs and desires in a creative way (Baker and Wang, 2006). Photographs are the main

32 source of data in a photovoice project and these images allow participants to construct their own

33 understandings and answers to the research questions.

34 While participatory photography and visual methods have existed in various research settings

35 under different names, the specific term 'photovoice' first emerged as an identified method of

36 research in health promotion and community development (Wang and Burris, 1997). Photovoice was

37 first used as a methodology to visually investigate women's health (Wang, 1999). The methodology

38 was developed with the understanding that photographs are valuable sources that hold a plethora of

39 information in a static image (Rose, 2012). Photographs have the ability to provide insights into

40 phenomena specified within a research study that are either unique or add to spoken and written

41 expressions and, crucially, work to position participants as creators and initial interpreters of data in

42 photovoice research (Carlson, Engebretson and Chamberlain, 2006). The data produced from

43 photographs, as well as semi-structured interviews or focus group discussions about the images,

44 provides an in-depth understanding of participants' realities. The goal of this process is to create a

45 reality where participants are integrated into the research not as passive providers of information, but

46 as co-creators of the knowledge produced from the research. The photovoice methodology allows for

47 a conscientious process of narrative creation through various interpretations of 'truth' based on the

48 framing of images and the accompanying iterative discussions between participants and researchers,

49 as well as between participants themselves (Burles and Thomas, 2014).

50 While the use of photovoice as a research methodology is context-specific and time-sensitive,

51 it is often initiated with a meeting between potential research participants and/or key stakeholders to

52 explore and identify relevant research questions. Once these areas have been identified and informed

53 consent to take part in the research has been confirmed, participants are usually involved in hands-on

54 workshops that explore how photography can be used as a form of communication, and in which they 
55 'brainstorm' ideas about how answers to the research questions can be displayed through images. At

56 this point participants are given digital or disposable analogue cameras, provided by the researchers.

57 Participants are shown how to use the cameras, given tips on how to take photographs through the use

58 of technical tricks such as lighting and angle, and discuss ethical issues of informed consent and

59 confidentiality related to recognisable photographs of people. Participants then head out into their

60 communities to take pictures. After a set period of time, participants and researchers meet as a group

61 (and/or potentially one-to-one) to share their images and react to other people's photos, relating back

62 to the research questions. This dialogue is the first stage of coding. The cycle of taking photos and

63 discussing them in a group and/or one-on-one interview setting continues in conjunction with the

64 project budget, timeline, resources, and participant availability.

65 Ethics and consent during a photovoice project is an ongoing process. While participants may

66 agree to take part in the onset of the project, this does not mean they are bound to continue, nor are

67 they required to show all their images to the group. Participants have the power to decide which

68 photographs are part of the research project and which are excluded. This power extends into the

69 dissemination of photographic data. The relationship of participants to photographic images is

70 complex and thus needs to be carefully considered.

72 Historical significance of photography in criminology: From mug shot to surveillance camera

73 Central to photovoice in criminological research is the use of photography within the

74 historical context of crime, not least in order to understand some of the issues relating to ethics and

75 sensitivity that arise from the use of photography as a means of making visible the stories of the

76 research participants. Many of the people who come under the gaze of the police or the criminal

77 justice system more widely have a fear of their images or profiles being captured and stored, for

78 justifiable reasons.

79 For more than a century the 'criminal' has been represented by the police and other agencies

80 in the criminal justice system through a police photograph or 'mug shot' (Carney, 2010). The police

81 photograph has become a notorious tool of the criminal justice system and of the media in the 
82 categorisation and stigmatisation of those who break the law. Early photographic representations have

83 been used in criminal justice not only for documentary and administrative purposes, but also to

84 abstract scientific data and records used for the construction of criminal identification and for

85 purposes of social control. Sekula (1986) in particular viewed photography as a bureaucratic-clerical-

86 statistical system which comprised an 'archive' whereby the visual was used to define the good, heroic

87 and celebrated as well as the deviant and criminal. Lombroso (1876) took visual representation to the

88 extreme by developing the discourse that criminality could be read from the body or facial

89 characteristics (Gibson and Rafter, 2006).

90 This process has expanded and become more complex with technological and scientific

91 developments, particularly over the last four decades. Now the photographic image is used for

92 investigation and confirming identity of suspects in combination with the DNA profile of the

93 criminal, fingerprints, retinal photographs and forensic crime scene analysis of images and victims.

94 The scope and power of these images is widespread because of digital imagery and technical

95 surveillance such as CCTV cameras commonplace in many countries. These practices can fuel

96 concerns that those with power capture and store images, photographs and prints in order label and

97 incriminate those on the margins of society. For example, the photographic images in the recent UK

98 riots of August 2011 demonstrated the power of the gaze of surveillance to give rise to labelling,

99 detection and conviction. For up to two years after the riots occurred the CCTV data was analysed and

100 used to track down and prosecute those involved in the disturbances (Newburn, 2014).

101 Bearing this in mind, it is understandable that some of the women approached to participate in

102 the photovoice projects described here reacted with reluctance and suspicion. After the initial

103 hesitancy, most participants quickly developed their ability to use photography to depict, interpret and

104 reinterpret their experience through the production of images. Some even chose to show their images

105 in public settings.

106

107 Disseminating photographic data

108 Showcasing participants' photographs from photovoice research in a public or semi-public

109 setting has the potential to be creative and empowering (Carr et al., 2015; Robinson, 2013). A key 
110 facet of photovoice is for the visual data to gain reach and create impact beyond academia. The

111 action-oriented outcome of photovoice provides a space for visual representation and re-

112 representation that potentially reaches larger audiences beyond those in the research community, or

113 those audiences contacted through conventional research outputs such as peer-reviewed journal

114 articles (O’Neill, 2004). This could manifest as a community forum or public (or semi-public)

115 photography exhibition. Sharing research not only provides a compelling platform to convey the

116 outcome of a research project, but can also act as a way to 'give back' to the community initiatives

117 that were involved in photovoice research (Mcintyre, 2003). The photovoice method has mainly been

118 used in health research, often with a focus on women's health (Bukowski and Buetow, 2011; Davtan

119 et al., 2016; Teti et al., 2012). The research discussed in this article is novel for its focus on

120 criminological aspects of women subject to supervision and injecting drug use amongst women. The

121 following section elaborates on two research projects in which the action-based outcomes promoted

122 participant empowerment and community and policy level awareness and engagement.

\section{Photography as empirical data}

124 The empirical findings discussed in the second half of this article are taken from two separate

125 criminological research studies carried out by the authors independently. Both authors used

126 photovoice as their central method for data generation.

127 The first author was involved in research exploring experiences of those subject to probation

128 supervision in communities in England. 'Supervisible', the title of a photovoice research project,

129 arose out of a paper presented at a meeting of the COST (European Cooperation in Science and

130 Technology) Offender Supervision in Europe Group in 2014. The views and narratives of those

131 subject to supervision have in the main been unheard. The emergence of 'mass supervision' has

132 largely escaped the attention of legal scholars and social scientists more concerned with the "mass

133 incarceration' reflected in prison growth (Phelps, 2013). Despite the fact that, even in the home of

134 mass incarceration, the number of people subject to probation or parole dwarfs the number

135 imprisoned; of the near 7 million people under correctional supervision in 2013 in the USA,

$1364,751,400$ were being supervised in the community (Glaze and Kaeble, 2014). Ministry of Justice 
137 (2014) figures from the UK show that in March 2014 in England and Wales, 218,671 people were

138 under probation service supervision; the prison population that month averaged 84,443.

139

140 The participants who were involved in this pilot study were volunteers from Alana House

141 Women's Centre in Southern England. The Centre provides support, advice and specialist offender

142 based programmes to both women on supervision and other marginalised women who had often

143 served prison or probation sentences. Ten women were involved and took photographs and then met

144 in focus groups to reflect upon and explore the reasons, emotions, and experiences that had guided

145 their chosen images. They were facilitated in this process by an artist experienced in group work. The

146 photographers wrote accompanying captions that described the meaning behind their images.

147 The second author's research explored how 'harm' and 'harm reduction' was defined and

148 understood by both women who injected drugs in Hungary and people who worked in social work

149 positions that delivered harm reduction interventions to these women. Harm reduction is a concept

150 that encompasses a response to illegal and legal drugs which aims to reduce the harms related to drug

151 use, rather than advocating the medicalisation or criminalisation of those using drugs (Marlatt, 1996).

152 Such responses include interventions, policies and specific programmes. A needle exchange

153 programme is a type of harm reduction service where people can exchange used syringes for new

154 ones. International evidence shows that syringe exchange programmes result in a public health benefit

155 by discouraging people from sharing needles when injecting, and therefore lessening their chances of

156 contracting and spreading blood-borne diseases such as HIV and hepatitis C (Wodak and Cooney,

157 2005). Existing research shows both a lack of gender-responsive harm reduction services worldwide

158 and a need for such services for women who inject drugs (Pinkham, Stoicesu and Myers, 2012).

159 In Hungary, a harm reduction centre in Budapest hosted a women-only syringe exchange

160 programme. This programme was referred to as 'Chicks Day' by the research participants. In addition

161 to the services offered by the harm reduction centre (which included a syringe exchange programme

162 for people of all genders), the women's programme Chicks Day provided a gendered safe space for

163 women and people who identified as women (including transgendered women). For the Hungarian

164 photovoice project described in this article, women who injected drugs and harm reduction employees 
165 of Chicks Day were given a mixture of digital and disposable cameras ${ }^{1}$ to document their experiences 166 and understandings of harm and harm reduction in 2013 and 2014. This research took place in the 167 context of the only gender-responsive harm reduction service for women who inject drugs in Hungary 168 (Chicks Day).

169 Both authors worked with research participants in the projects to create photo exhibitions that 170 showcased a selection of the photographic data. The Budapest-based research event was a public 171 photo exhibition that raised money for the Chicks Day programme and also celebrated the fourth 172 anniversary of the programme's existence. This event included public comments by the coordinator of 173 Chicks Day, the communications manager of the harm reduction centre and the researcher, and a 174 public viewing of an independent video made about Chicks Day from 2013.

175 The Supervisible project images were exhibited in three exhibitions. The first exhibition was 176 held at the Women's Centre in Southern England, and the second exhibition was in Brussels and a 177 third was hosted in Glasgow. The first exhibition was attended by participants, their families, 178 practitioners and local policy makers, and politicians. The second exhibition was held to celebrate and 179 showcase the achievements of the COST research network and the Supervisible project not just in 180 England but also in Scotland and Germany. One of the research participants and the Women's Centre 181 manager were also invited and flown out to Brussels where they gave a presentation discussing their 182 experiences of the research study and their own narratives. The exhibition was visited by the general 183 public, politicians and commission staff as well as participants of the COST network and their 184 colleagues. The Glasgow exhibition involved participants and their families as well as professionals 185 and the general public.

186 Both research projects were approved by the relevant academic institutions' ethical review 187 boards at Redacted for Peer Review and the Redacted for Peer Review prior to the start of data 188 collection. The first author also received ethical approval from the Howard League for Penal Reform. To protect anonymity, all participant names used in this article are pseudonyms.

190

${ }^{1}$ As a result, the pixel quality of the images varies, with the disposable camera images having a lower resolution and a poorer overall picture quality. 


\section{Common themes of the visual data}

Independent analysis of the visual data and qualitative interviews from the two research

193 projected yielded some overlapping themes. The images shown and described below were part of the

194 larger portfolio of images showcased in the public photograph exhibitions outlined in the previous section. The eight images in this article were specifically selected by the two authors based on four

196 themes that emerged from a series of discussions about the Supervisible and Chicks Day photovoice

197 projects. These discussions included viewing and commenting on each other's visual data, the

198 participants' social contexts, and the analytic implications of the projects. The common themes from both projects are: surveillance and control, judgment and representation, rubbish and waste, and help and support.

Surveillance and control: Supervisible project

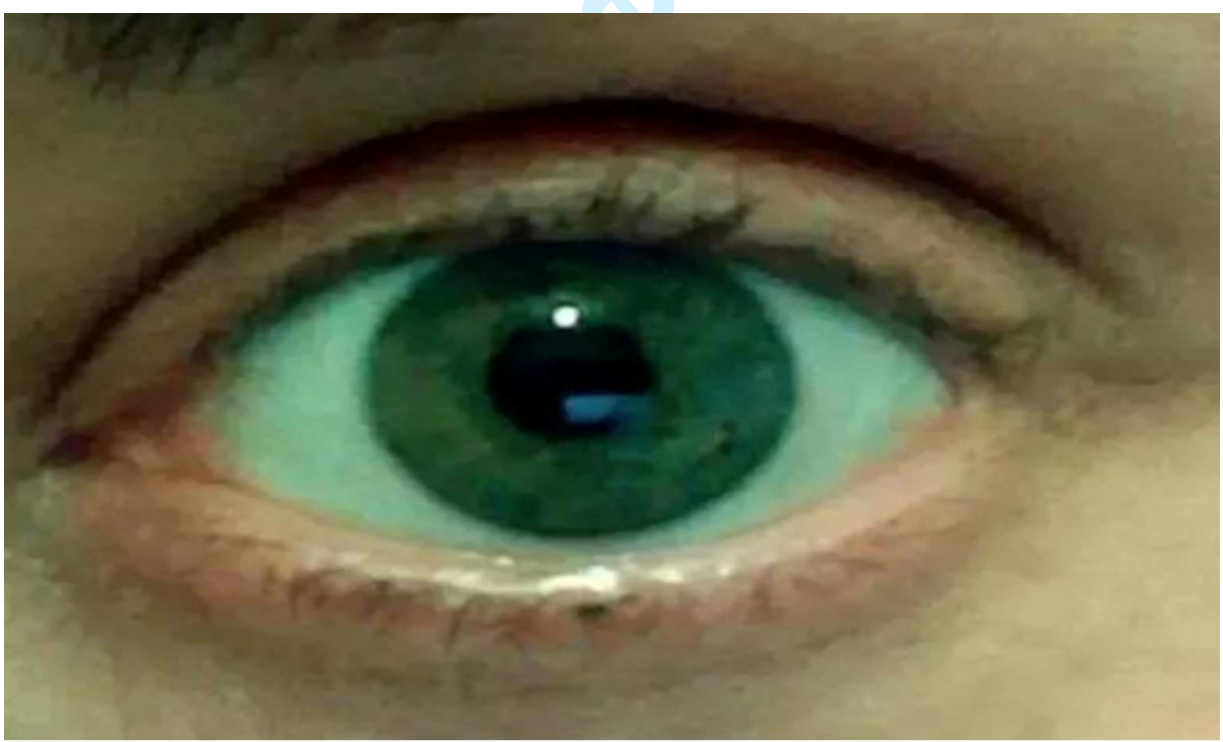

204 Image A. 'Sobriety’. Image taken by Jenny, a participant on supervision.

Image A, a close up of a human eye titled 'Sobriety', conveys a strong sense of the pains of

community punishment, not just during the moments of active supervision but the pervasive nature of the all-seeing eye of punishment in the community. However, for Jenny, who had a history of alcohol 
210 bloodshot veins symbolised her successful new healthy lifestyle. At the same time, Image A is a

211 metaphor of how the lives of participants of supervision are exposed to others who have power over

212 them in the form of the courts, probation, social workers or the police. Image A and a number of other

213 photographs created during the Supervisible project had a similar theme of participants under

214 supervision experienced their lives being halted - their 'real life' felt suspended during and sometimes

215 after supervision. The quote by another research participant, Emily, illustrates this point:

216

...going to probation and talking about the way you ought to react as a woman isn't real life. You'd like it to be and at some point hopefully subconsciously it will be but realistically you don't walk down the street and go oh I mustn't react in this way or...

The sense of a panoptical all-seeing gaze wherever participants sought refuge was never far away

222 (Foucault, 1977; Cohen, 1985). Both Emily and Jenny were continually conscious of needing to

223 present their behaviour in a certain way, of being exposed and monitored while their very gendered existence was being assessed as 'deviant' or failing to conform to the norm for women.

While image A draws on popular motifs in the context of the penal system, the image contrasts with common descriptions of what supervision or social work means within the community.

227 Many of the women's photographs and discussions during the Supervisible project, revealed that their 228 interaction was depicted as exposing, as the stark eye of image A suggests. Participants explained

229 how even when the relationship with the supervisor or formal support worker was positive, the association merely served to mitigate the pains of being compelled or constrained to obey authority. Image A, however, as Jenny reflected during the focus group the constraint and monitoring of 232 supervision had enabled her to access the support she required to stop drinking alcohol which had 233 improved her health.

234 One of the most common themes to emerge from both the Supervision and Chicks day 235 projects was 'constraint' and 'control'. This emerged in images and discussions centred on limited 236 freedom, on living under surveillance and regimes of control, on the constant perception of being 237 watched or supervised and on the barriers that this sense of surveillance imposed on living a full and 
238 'normal' life. Indeed, for some of the women in both the English and Hungarian research projects, the

239 fear of being incarcerated or involved with the police was ever present.

240

241 Surveillance and control: Chicks Day project

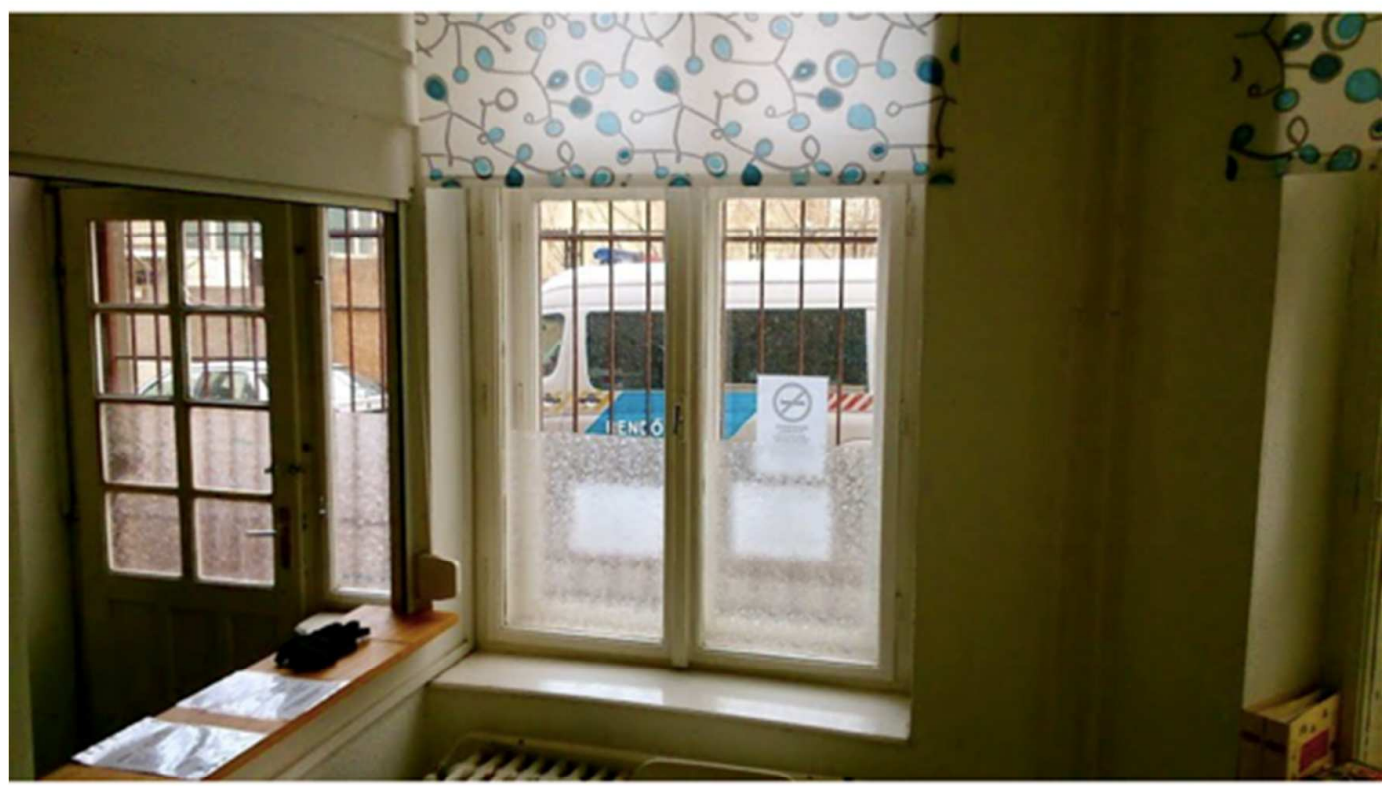

242

243 Image B. 'Don't inject dope, because you'll be taken by the police'. Image taken by Chicks Day 244 employee Bora.

245

246 Image B was one of a series of images with the same title that were taken by research

247 participants. This series features the police presence in the Hungarian neighbourhood where the harm

248 reduction centre was located. The 'don't inject dope' photographs showcase the visible presence of

249 police surveillance in the lives of the employees and clients of the women's programme and the harm

250 reduction centre. Image B shows the inside of the harm reduction centre looking out through the

251 barred windows to the top of a police van parked across the street. The title of image B, 'don't inject

252 dope, because you'll be taken by the police', is a warning message that reflects the drug laws in

253 Hungary that criminalise the act of consuming illegal drugs. While many countries have punitive 
254 responses to individuals possessing or selling illegal drugs, penalising drug use in and of itself is a

255 particularly strict Hungarian law aimed at controlling 'deviant' citizens. In image B, the police car

256 symbolises the threat of this penalisation for clients of the women's programme.

257 Image B was a common sight outside of the harm reduction centre, with police parked outside

258 or across the street from the centre typically at least once a week. The harm reduction centre had a

259 written agreement with the police that stated officers would not stop and search the harm reduction

260 centre's clients within a one-block radius of the harm reduction centre, but after a few years the

261 agreement was ignored by the police and their presence in the area increased. In Hungary, anyone can

262 be stopped and searched without the police needing to give any 'reasonable cause'. Furthermore, an

263 individual can be fined if the act of stop and search reveals drug paraphernalia, including syringes and

264 needles. If someone has unpaid fines from multiple offences that add up to more than a certain

265 monetary amount, then the individual can be arrested. As one of the main purposes of the harm

266 reduction centre and the women's programme were to provide a facility for the exchange of used

267 syringes and needles for new ones, clients of the centre were almost always in possession of drug

268 paraphernalia, and therefore vulnerable to police punitive action. The employees of the women's

269 programme found that the police's general unwillingness to cooperate with the centre made the harm

270 reduction service delivery more stressful and challenging. Chicks Day client Flora responded to image

271 B by stating that the police "would like to show: "we are here, and we are the man here" through

272 their imposing and intimidating presence in the neighbourhood. The police presence was connected to

273 clients' fear of judgment, which is also the next theme from both research projects.

275 Judgment and representation: Supervisible project

276 


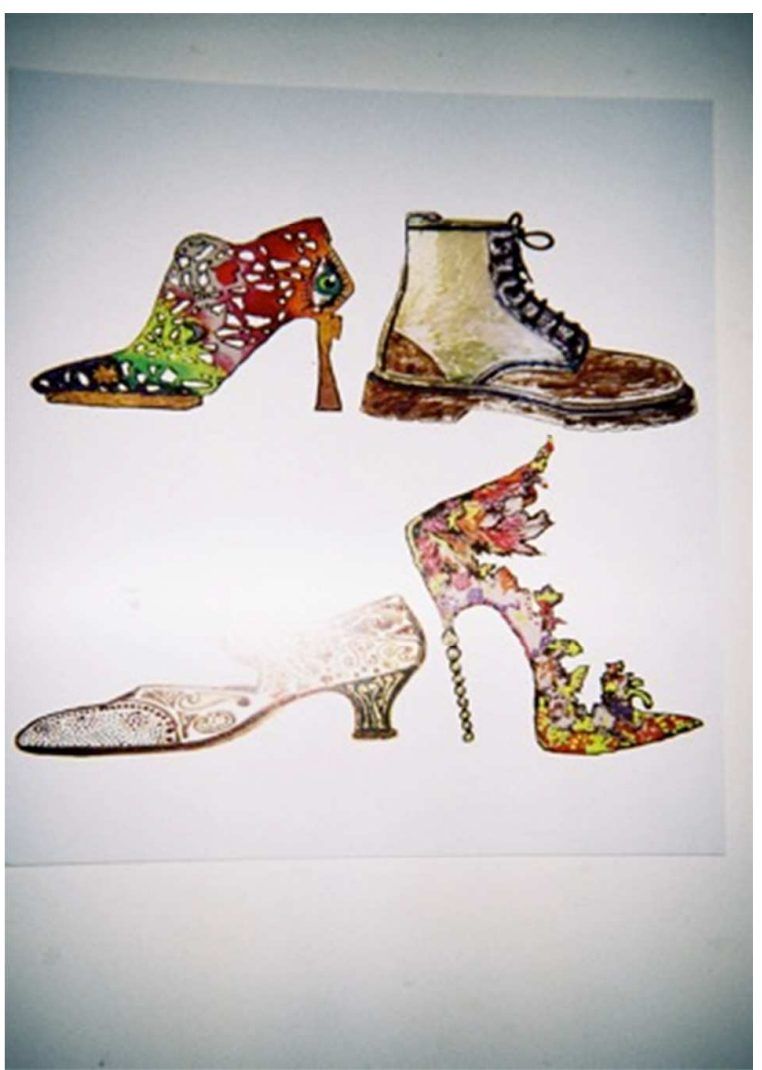

Image C. 'You never know a person until you walk a mile in their shoes'. Image taken by Betty, a participant on supervision.

Judgment, labelling, and stigmatisation were particular and common themes in the images taken by participants in both the Supervisible and Chicks Day projects. Betty, one of the women from England involved in the Supervisible project, reflected on her criminal justice journey in reference to image $\mathrm{C}$, a painting featuring four different types of women's shoes. The shoes are almost eccentrically individual with respect to various styles and designed for different purposes. Betty commented on image $\mathrm{C}$ being “about the whole judgment -- you shouldn't -- you don't know a man until you've walked a mile in his shoes". Thus she pointed to the stereotypical nature of any criminalising judgment which assigned characteristics and traits based on one aspect of a person's life or appearance. She referred to 'man' and 'his' shoes although obviously she was considering her experience which mirrors attitudes regarding gendered experiences of criminal justice being male predominately male. This process has become standardised via technologies which deconstruct offenders into characteristics which are then scored for risk assessment and resource allocation purposes (Fitzgibbon, 2007, 2008). This in itself was viewed as unjust, ultimately a failure to represent the whole person accurately. As Katja Franco Aas (2004: 386) argues, the criminalised 
individual is deconstructed into a series of data or observable traits which serve to make a "dividual' which then operates to displace the context of the person's life. Ideas of representation and judgment were seen by the women to reinforced this lack of contextual understanding.

Image $\mathrm{C}$ was one of a collection of images in the Supervisible project that presented the themes of representation and judgment. Sally, another research participant, claimed that being on probation means "you are being someone you are not" or "being seen as someone you are not". However, other participants stated that probation also involves taking their masks off - a process which can ease a burden of misrepresentation. As participant Mandy stated, "it was quite a relief when someone actually said 'It's all right, we know what's going on and you don't have to pretend anymore, [who] you are'". Desistance studies and the resultant literature which focused on strengthbased approaches has repeatedly illustrated the importance of genuine communication and acceptance (Maruna et al., 2004; Burnett and McNeill, 2005; Fitzgibbon, 2007). Image C and other visual data on judgment highlight the importance of the research participants' personal relationships with their probation officer. The probation officer's ability to see the real person and their complex life - the exact opposite of deconstruction and stereotyping - was spoken about as key for participants to overcome the negative aspects of monitoring while under supervision.

\section{Judgment and representation: Chicks Day project}

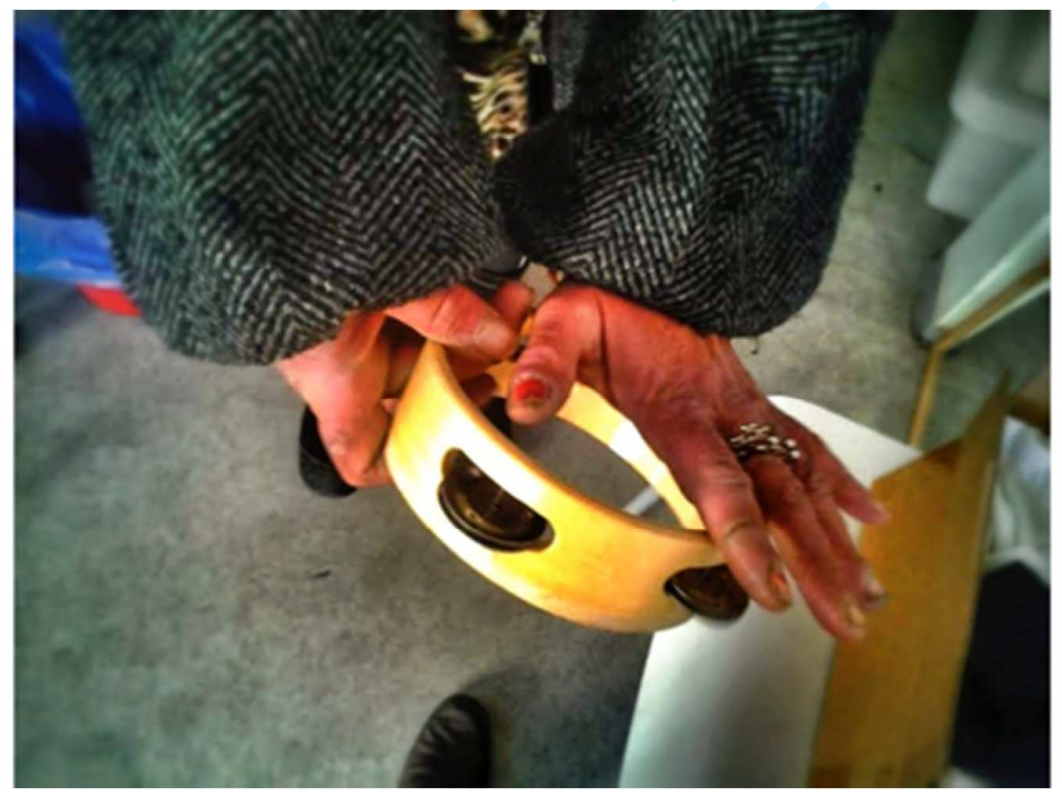

Image D. 'Trinkets'. Image taken by Chicks Day employee Milla. Image D captures a client at the Hungarian women's programme playing a tambourine. The tambourine was donated to Chicks Day, which accepted clothing, shoe, and toy donations for both 
319 their clients and their clients' children. Image D is one in a series of photographs called 'trinkets'.

320 This series of images are compiled mainly from the jewelry worn by clients of the women's

321 programme at the harm reduction centre. A client said that image D captured the essence "to dance

322 freely and without worry". This lighthearted reading of image D was not however shared by the

323 photographer, who worked at the harm reduction centre. The photographer and other Chicks Day

324 employees feared that image D could potentially be framed and interpreted within archetypal sexist

325 and racist constructions of Roma women.

326 The vast majority of the client population who accessed the women's programme identified

327 as Roma. Roma people are far from a homogenous group, even within Roma communities living in

328 Hungary. However, the Roma of Central and Eastern Europe are often romanticised in popular media

329 in much of the world as either 'noble savages' who are characterised as fantastical and mysterious, or

330 (and often as well) Roma the 'bogeyman' who should be feared and criminalised (Tremblett, 2013).

331 The tambourine-playing Roma woman fits into the former category. In many parts of Europe, people

332 who are ethnically Roma have suffered from a long and painful history of prejudice, marginalisation,

333 and racially motivated violence (Hancock, 2007). Physical and economic harms disproportionately

334 affect Roma people, in part because they face ethnic discrimination and cultural risks by virtue of

335 being Roma, and such harms are exacerbated for people who inject drugs (Grund, Öfner and

336 Verbraeck, 2000; Rácz et al., 2012). The Chicks Day employees feared that image D reproduced

337 stereotypical imagery of Roma women and misrepresented their client population. This fear led to a

338 debate among the employees as to whether image $\mathrm{D}$ should be selected for the public photo

339 exhibition. After lengthy discussion, image D was included as part of the public photo exhibition as a

340 poignant visual commentary on the representation of Roma women. Furthermore, image D provoked

341 a critical discussion and reflection by the employees on the judgment and representation of their client

342 base.

343

344 Rubbish and waste: Supervisible project 
1

2

3

4

5

6

7

8

9

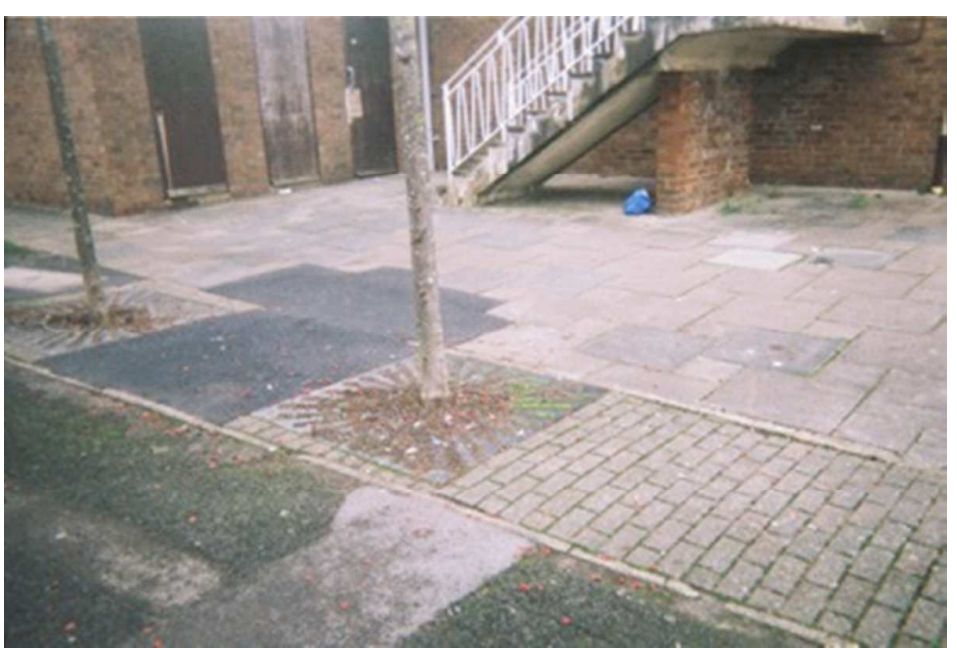

Image E. Untitled. Image taken by Rebecca, a participant of the women's centre.

Many of the photographs taken by women in both the English and Hungarian research

projects depicted images of litter, rubbish, bins, discarded newspapers, ashtrays with cigarette butts, empty alcohol cans and bottles, and discarded syringes. Participants discussed how the idea of debris either represented their lives, or a situation or an aspect of their lives. Photographers of this theme of images commonly spoke of feeling like rubbish or shit, feeling all used up and having a sense their lives were rubbish and they were worthless. Rebecca, one of the women from the Women's Centre in the Supervisible project, took a photo of a blue bag of rubbish that was tiny and hidden under a stairway. She explained

I was trying to get the rubbish of my life, like the bag, here, this. Everything else is clean and I'm the rubbish and I was trying to get that in this one [...] There's clean and there's that rubbish, and I'm that $[\ldots]$ Before probation, yeah, really did [feel like that]!

Societal judgements on 'deviant' woman as abnormal can result in self-stigmatisation, where the individual internalises these judgments and results in a deterioration of self-esteem and self-worth (Heidensohn et al., 1985; Measham, 2002). Rebecca for example had suffered long-term mental health problems which exacerbated her complex material problems, making her focus on her own 
364 failings rather than being able to build on her strengths. Rebecca's participation in the Supervisible

365 photovoice project enhanced her self-confidence to become more engaged in other support groups. 366

Rubbish and waste: Chicks Day project

368

369

370

371

372

373

374

375

376

377

378

379

380

381

382

383

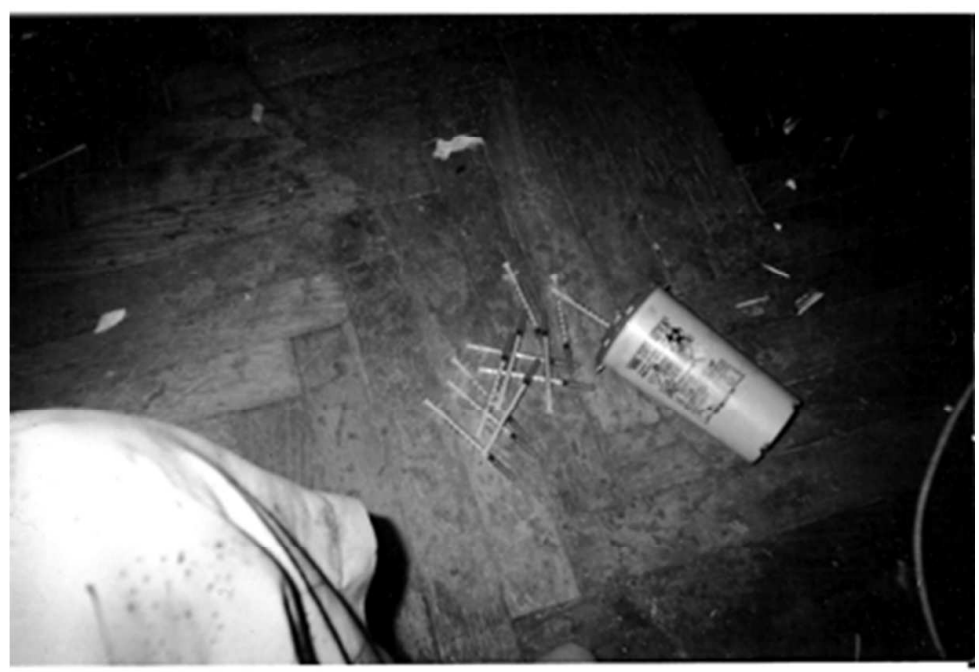

Image F. 'Watch out for others, use the badella!' Image taken by Chicks Day client Anikó.

In the right half of image $\mathrm{F}$, an arrangement of syringes and a cylindrical safe syringe deposit container (known as a badella in Hungarian) lay on a hardwood floor. The photographer's knee protrudes in the bottom left side of the image. Anikó, the photographer of image F and a client of Chicks Day, took the image in response to feeling upset that some people discarded their used syringes onto public streets. Anikó wanted to show what "correct using looked like", meaning the 'right' way to dispose of used syringes after injecting was to place them in the badella rather than throw them on the ground. Distributing personal badellas is one of a number of strategies used in harm reduction interventions to collect and safely dispose of used needles and syringes. Another client commented how “it's disgusting people just throw their needles on the ground, don't they care?”.

Taboos surrounding hygiene, uncleanliness, and disease transfer have long been associated with people who use drugs, especially people who inject (Fitzgerald and Threadgold, 2004;

Simmonds and Coomber, 2009). By extension, the image of a syringe represents these fears, and 
1

2
384 specifically the anxiety around an accidental needle prick of a publically discarded syringe. Such fears 385 were exacerbated when a syringe was found discarded in a park in the neighbourhood surrounding the 386 harm reduction centre where the women's programme was located. The discarded syringe fuelled outrage within a citizen's group who argued for the harm reduction centre to be shut down. This panic

Help and support: Supervisible project

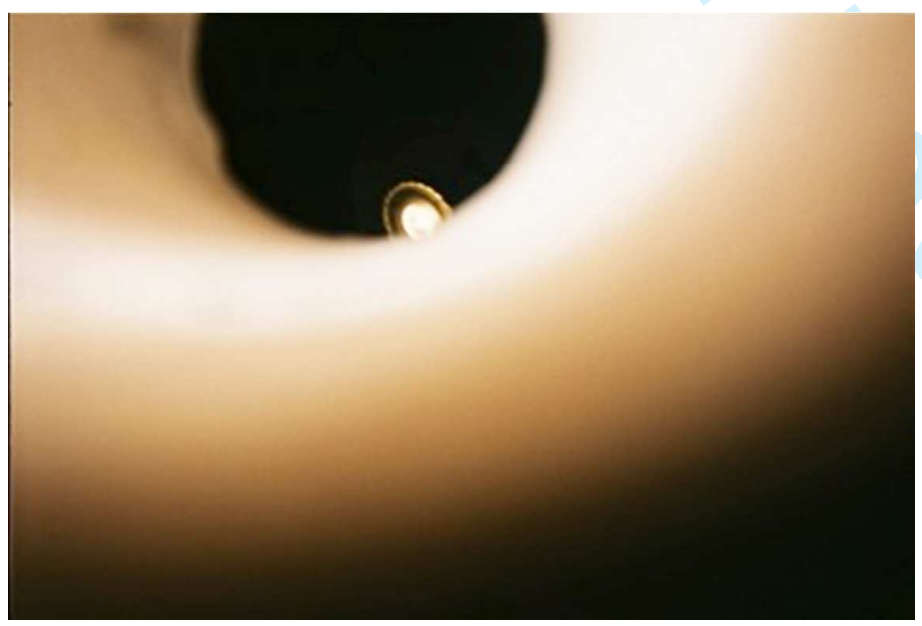

Image G. 'Light at the end of the tunnel'. Image taken by Sophie, a participant on supervision.

While participants in both the Supervisible and Chicks Day research projects were women overall in vulnerable life situations, a selection of photographs highlighted positive experiences of receiving support and advice and accessing a safe space. Connected to the help and support was the strong sense that the women were resilient, they were moving forward, and making positive changes 
405 to their lives with support and encouragement from their probation officers or the workers in the

406 women centres.

407 Describing image G, Sophie said "I quite like the way that it sort of just peeks out, rather than

408 being there and whatever else. It's sort of quite muddling through, it seems quite far away there,

409 which is actually how it felt". Sophie, who was on supervision, demonstrated her awareness of the

410 challenges ahead. Yet despite this, Sophie recognised that positive changes in her life were possible

411 with adequate support. Her conceptual perspective, evident in image G, indicate her hopes for the

412 future.

413 One of the most engaging elements of the Supervisible project was how the photovoice

414 method facilitated a space for participants to tap into their latent creativity not just through the visual

415 research, but also to link their experiences to their future goals and life directions. Jenny encapsulated

416 the desired achievements of many women who participated in this research project. She explained

417 how the services offered at the women's centre encouraged her to try "to be more creative, you know,

418 actually doing something as opposed to just talking about it... It just really cheers me up". Since

419 participating in the Supervisible project, Jenny presented her photographs at the Brussels exhibition

420 and spoke to an audience of over ninety people. Later she was accepted on a fine arts degree course

421 based on her portfolio of creative work. Other participants in the Supervisible project engaged in art

422 classes locally, prompted by the encouragement and support of the women's centre targeting women

423 in supervision.

424

425 Help and support: Chicks Day project

426

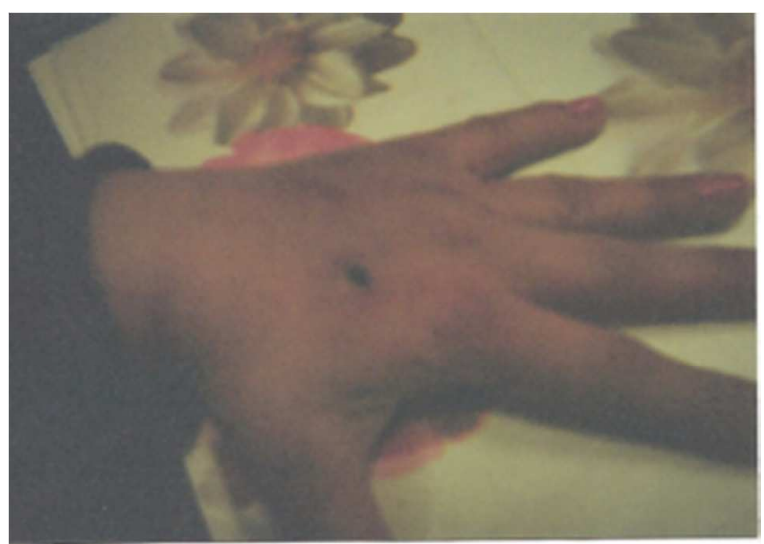


427 Image H. 'Teamwork, paying attention'. Image taken by Chicks Day client Csilla.

428

429

Image H, taken by Chicks Day client Csilla, shows her own hand spread out on a table. Csilla

took this photo to show the abscess in the middle of her hand. She explained how when she first came

431 into the harm reduction centre with the sore, multiple employees asked her what happened, and

432 offered to help make the wound sterile. She saw this as an example of "team work" and "paying

433 attention" on the part of the women's programme employees. Csilla was one of a chorus of clients

434 who praised the help and support they received from employees. This support was typical harm

435 reduction delivery, such as working on the public syringe collection outreach team, and linking clients

436 up with other services (dentistry, hospital, housing shelters, etc.). In addition to this, the clients spoke

437 of how the Chicks Day employees went "above and beyond" their roles. Csilla specifically noted the

438 women's programme employees as "show[ing] me my potential". Csilla was a regular visitor at the

439 women's programme, and dealt with various issues in her life including unstable housing and

440 violence. With the help of the women's programme employees, Csilla was able to find legal

441 employment. While linking clients with services was one of the roles of the Chicks Day employees,

442 the weekly contact which facilitated attention to the details of clients' lives meant the employees

443 developed empathetic relationships beyond their role.

444 The employees' effort "above and beyond" was crucial for fostering a safe space during

445 Chicks Day. This space allowed clients to feel comfortable not only in accessing the services on offer

446 at the women's programme, but also to return to the services on a regular basis. The weekly

447 programme had a dedicated client base of between 40 and 50 women. People who inject may be

448 deterred from accessing health and social services, in part due to past experiences or fear of

449 discrimination and stigmatisation (Ahern, Stuber and Galea, 2007; Wilson et al., 2014). Barriers to

450 accessing services are often compounded for women who inject drugs due to lack of gender-specific

451 harm reduction services (Pinkham, Stoicesu and Myers, 2012). By 'paying attention' to clients

452 'through team work', the women's programme employees gained valuable contexts in which they

453 delivered harm reduction services and created a supportive environment for (mainly) women who

454 injected drugs, within the harm reduction centre's financial constraints. The discussion with Csilla 
455 and title of image $\mathrm{H}$ with the photographer is a product of Chicks Day as a safe space.

456 These various images and themes are a selection of the photographic data that was produced

457 from the Supervisible and Chicks Day research projects. These images show that although the process

458 of support and advice provided to women could be helpful and promote recovery or desistance, this

459 engagement was often also experienced as painful and intrusive. Through the themes of judgment,

460 surveillance, and control, the photographic data and discussions revealed the pervasive and invasive

461 nature of women's experiences of the criminal justice system and the women centres' they attended.

462

\section{Concluding thoughts}

464 The two research projects discussed in this article have shown that photovoice is an effective

465 and forceful means of enlightening the public, relevant practitioners, and policy makers on the

466 complex realities of people involved in rehabilitation supervision and harm reduction.

467 Since research participants are the photographers in photovoice projects, they ultimately have

468 ownership of the images they produced. However, the authors of this article have reproduced their

469 images in various media, including public presentations, exhibitions, and journal articles. Ethical and

470 legal safeguarding was ensured by both authors in order to protect research participants' image

471 ownership. For the first author's Supervisible project, all the research participants signed consent

472 forms about the use of their photographs for exhibitions, articles and other outputs, but they retained

473 their ownership if the image was to be used for other purposes or was commercially used or

474 successful. The women were keen for their pictures to be viewed and discussed by a wider audience

475 and fully understood the safeguards in terms of identity and ownership. The photographs associated

476 with the second author's Chicks Day research in Hungary are copyright under a Creative Commons

477 license CC BY-NC-ND 4.0. This Creative Commons license means that the images can be shared,

478 copied or redistributed if appropriate credit is given to the authors of the images (as cited in the

479 publications). Images cannot be used for commercial purposes nor can the images be altered and

480 distributed. Both the researcher and the research participants have reused the photographs since the

481 Hungarian research was completed.

482 The methodological strength of photovoice is that participants hold the power to take 
483 photographs of whatever they choose, and these images ultimately guide the generation of materials

484 and analysis of the photovoice research. The first and second authors both found that their respective

485 research projects facilitated space for participants to be empowered as co-producers through the data 486 generation and knowledge creation processes, as well as through the public photo exhibitions. While

487 the authors enthusiastically endorse the potential of photovoice for criminological research, this

488 endorsement comes with a warning that this is not an utopian methodology that removes all inherent 489 power inequalities in research and can promise social change. As with other forms of qualitative and 490 participatory research, photovoice should be used with ethical care and active researcher reflexivity 491 (Pink, 2007). Furthermore, the concept of participant empowerment through photovoice should be 492 realistically framed within the structural and material conditions that might disempower participants 493 in their lives. However positive the immediacy of photovoice may yield, the overarching sense of 494 distress, powerlessness and destruction revealed through the participants' pictures heralds the need for 495 structural and political change which can sustain permanent transformation in their lives. For 496 example, the seemingly innocuous photograph of a tambourine in image D symbolises both a 497 celebration of culture while also reproducing a sexually imbedded racist stereotype. The interpretation 498 of image D depends on the contextual positioning and awareness of the audience viewing the 499 photograph. Photovoice research facilitates space for contradictory interpretations to co-exist through 500 within one image, and through this process can reveal and challenge inherent power inequalities.

501 These two research projects demonstrate how photovoice is a promising methodology for 502 undertaking criminological research with women. In this article we have shown how two separate 503 photovoice projects on key areas of criminological research (drug use and rehabilitation supervision) 504 produced rich visual data with thoughtful insights. Crucially, the evidence was generated by the 505 women themselves. The photographic data challenges stereotypical views about the lack of agency for 506 many of the women involved in these studies, and highlights how a critical approach to visual 507 criminology has emancipatory potential. 
511 The authors would like to thank Carolyne Kardia and Laura McDavitt for their contribution to the

512 Supervisible project, the women who participated in the Chicks Day project and the Supervisible

513 Project and Janet Ransom for her assistance with this article.

514

$515 \quad$ Funding

516 The Supervisible project was a pilot study funded by the Howard League for Penal Reform which

517 uses photography to understand the experiences of those subjected to community supervision. The

518 network engaged in the project was supported by COST (European Cooperation in Science and

519 Technology) Offender Supervision in Europe Group. The research undertaken by the second author

520 during Chicks Day was supported by an Erasmus Mundus Fellowship, awarded by the Educational,

521 Audiovisual and Culture Executive Agency of the European Union.

522

523 


\section{References}

525 Aas, K.F. (2004) 'From narratve to database: Technological change and penal culture'. Punishment

526 and Society, 6,379-393

527

528 Ahern, J, Stuber, J and Galea, S (2007) Stigma, discrimination and the health of illicit drug users.

529 Drug and Alcohol Dependence 88(2-3): 188-196.

530

531 Baker, T and Wang, C (2006) Photovoice: Use of a participatory action research method to explore

532 the chronic pain experience in older adults. Qualitative Health Research 16(10): 1405-1413.

533

534 Belknap J (2014) The Invisible Woman: Gender, Crime, and Justice. Stamford, CT: Cengage 535 Learning.

536

537 Birkett G (2016) Gender, awareness of what they actually do: Use of a participatory action research 538 method to explore the chronic pain experience in older adults. Criminology and Criminal Justice 539 16(4): 497-512.

540

541 Burles, M and Thomas, R (2014) “I just don't think there's any other image that tells the story like 542 [this] picture does": Researcher and participant reflections on the use of participant-employed 543 photography in social research. International Journal of Qualitative Methods (13): 185-205. 544

545 Burnett, R and McNeill, F (2005) The place of the officer-offender relationship in assisting offenders 546 to desist from crime. Probation Journal (52)3: 221-242.

547

548 Bukowski, K and Buetow, S (2011) Making the invisible visible: A photovoice exploration of 549 homeless women's health and lives in central Auckland. Social Science and Medicine (72)5: 739-746.

550

551 Carlson, E, Engebretson, J and Chamberlain, R (2006) Photovoice as a social process of critical 552 consciousness. Qualitative Health Research (16)6: 836-852.

553

554 Carney, P (2010) Crime, punishment and the force of photographic spectacle. In: Hayward KJ and 555 Presdee M (eds) Framing Crime: Cultural Criminology and the Image. Abingdon, Oxon; New York, 556 NY: Routledge, pp. 17-35. 
558 Carr, N, Bauwens, A, Bosker, J, Donker, A, Robinson, G, Sucic, I, and Worrall, A (2015) Picturing

559 probation: Exploring the utility of visual methods in comparative research. European Journal of

560 Probation (7)3: 179-200.

561

562 Cohen, S (1985) Visions of Social Control. Cambridge: Polity Press.

563

564 Fals-Borda, O and Rahman, MA (eds) (1991) Action and Knowledge: Breaking the Monopoly with

565 Participatory Action Research. New York: Apex Press.

566

567 Fitzgerald, J and Threadgold, T (2004) Fear of sense in the street heroin market. International Journal

568 of Drug Policy (15)5-6:407-417.

569

570 Fitzgibbon, DW (2007) Risk analysis and the new practitioner: Myth or reality? Punishment and

571 Society $9(1): 87-97$.

572

573 Fitzgibbon, DW (2008) Fit for purpose? OASys assessments and parole decisions. Probation Journal

574 55(1): 55-69.

575

576 Foucault M (1977) Discipline and Punish: The Birth of the Prison. London: Allen Lane.

577

578 Gibson, M and Rafter, NH (2006) Criminal Man: Cesare Lombroso. Durham and London: Duke

579 University Press.

580

581 Glaze, LE and Kaeble, D (2014) Correctional populations in the USA, 2013. Bureau

582 of Justice Statistics, Office of Justice Programs, Washington, DC: Department of

583 Justice. Available at: http://www.bjs.gov/content/pub/pdf/cpus13.pdf

584

585 Grund, JP, Öfner, P and Verbraeck, H (2000), Marel o Del, Kas Kamel, le Romes Duvar (God Hits

586 Whom he Chooses; the Roma Get Hit Twice). An Exploration of Drug User and HIV Risks Among the

587 Roma of Central and Eastern Europe. New York: Open Society Institute.

588

589 Heidensohn, F, Silvestri, M and Campling, J (1985) Women and Crime. Macmillan London.

590 
591 Kende, Á (2000) The Hungary of otherness: The Roma (Gypsies) of Hungary. Journal of European

592 Area Studies (8)2:187-201.

593

594 Kindon, S, Pain, R, and Kesby, M (eds) (2007) Participatory Action Research Approaches and

595 Methods: Connecting People, Participation and Place. London: Routledge.

596

597

Kóczé, A (2009) Missing Intersectionality: Race/Ethnicity, Gender and Class in Current Research

598 and Policies on Romani Women in Europe. Budapest: Center for Policy Studies, Central European 599 University.

600

601

Marlatt, G. (1996) Harm reduction: Come as you are. Addictive Behaviors (2)6: 779-788.

602

603 Maruna, S and Porter, L and Carvalho, I (2004) The Liverpool desistance study and probation

604 practice: Opening the dialogue. Probation Journal 51(3): 221-232.

605

606 Measham, F (2002) "Doing Gender" - "Doing drugs": Conceptualiszing the gendering of drugs

607 cultures. Contemporary Drug Problems (29): 335-373.

608

609 Matrix (2014) Roma Health Report: Health Status of the Roma Population. Data Collection in the 610 Member States of the European Union. European Commission. Available at:

611 http://ec.europa.eu/health/social_determinants/docs/2014_roma_health_report_en.pdf

612

613 McIntyre, A (2003) Through the eyes of women: Photovoice and participatory research as tools for 614 reimagining place. Gender, Place and Culture (10)1: 47-66.

615

616 Musoke, D, Ndejjo, R, Ekirapa-Kiracho, E and George, A (2016) Supporting youth and community

617 capacity through Photovoice: Reflections on participatory research on maternal health in Wakiso

618 district, Uganda. Global Public Health (11)5: 683-698.

619

620 Newburn, T (2014) The 2011 England riots in recent historical perspective. British Journal of

621 Criminology (55)1: 39-64.

622

623 Parkin, S (2014) An Applied Visual Sociology: Picturing Harm Reduction. London: Ashgate. 
625 Phelps, M (2013) The paradox of probation: Community supervision in the age of mass incarceration

626 Law and Policy 35(1-2), 55-80.

627

628 Pink, S (2007) Doing Visual Ethnography: Images, Media and Representation in Research (Second

629 Edition). London: SAGE Publications.

630

631 Pinkham, S, Stoicescu, C, and Myers, B (2012) Developing effective health interventions for women

632 who inject drugs: Key areas and recommendations for program development and policy Advances in

633 Preventive Medicine (2012): 1-10.

634

635 Rácz, J, Márványkövi, F, Petke, Z, Melles, K, and Légmán, A (2012) The barriers to obtaining

636 treatment for Roma and Non-Roma intravenous drug users in Budapest, Hungary: A group

637 comparison New Medicine (16)2: 52-62.

638

639 Reason, I and Bradbury, H (eds) (2001) Handbook of Action Research: Participatory Inquiry and

640 Practice. London: SAGE Publications.

641

642 Robinson, N (2013) Picturing social inclusion: Photography and identity in downtown eastside

643 Vancouver. Graduate Journal of Social Science (10)2: 20-42.

644

645 Rose, G (2012) Visual Methodologies: An Introduction to Researching with Visual Materials. $3^{\text {rd }}$

646 Edition. London: SAGE Publications.

647

648 Simmonds, L, and Coomber, R (2009) Injecting drug users: A stigmatised and stigmatising

649 population. International Journal of Drug Policy (20)2: 121-130.

650

651 Strathdee, S and Vlahov, D (2001) The effectiveness of needle exchange programs: A review of the

652 science and policy. AIDScience, 1/16. Available at: http://aidscience.org/Articles/aidscience013.asp

653 [Accessed 5 June 2012].

654

655 Teti, M, Murray, C, Johnson, L and Binson, D (2012) Photovoice as a community-based participatory

656 research method among women living with HIV/AIDS: Ethical opportunities and challenges. Journal

657 of Empirical Research on Human Research Ethics (7)4: 34-43.

658 
1

2

3

4

5

6

7

8

9

10

11

12

13

14

15

16

17

18

19

20

21

22

23

24

25

26

27

28

29

30

31

32

33

34

35

36

37

38

39

40

41

42

43

44

45

46

47

48

49

50

51

52

53

54

55

56

57

58

59

60
659 Wang, C (1999) Photovoice: A participatory action research strategy applied to women's health.

660 Journal of Women's Health 8(2): 185-192.

661

662 Wang, C, and Burris, M (1997) Photovoice: Concept, methodology, and use for participatory needs 663 assessment Health Education \& Behavior (24)3:369-387.

664

665 Wilson, H, Brener, L, Mao, L and Treloar, C (2014) Perceived discrimination and injecting risk

666 among people who inject drugs attending needle and syringe programmes in Sydney, Australia. Drug

667 and Alcohol Dependence (144)1:274-278.

668

669 Wodak, A and Cooney, A (2005) Effectiveness of sterile needle and syringe programmes.

670 International Journal of Drug Policy (16)1: 31-44. 


\section{Women's voices made visible:}

Photovoice in visual criminology

Images for article - 8 photographs -7 colour and 1 black and white

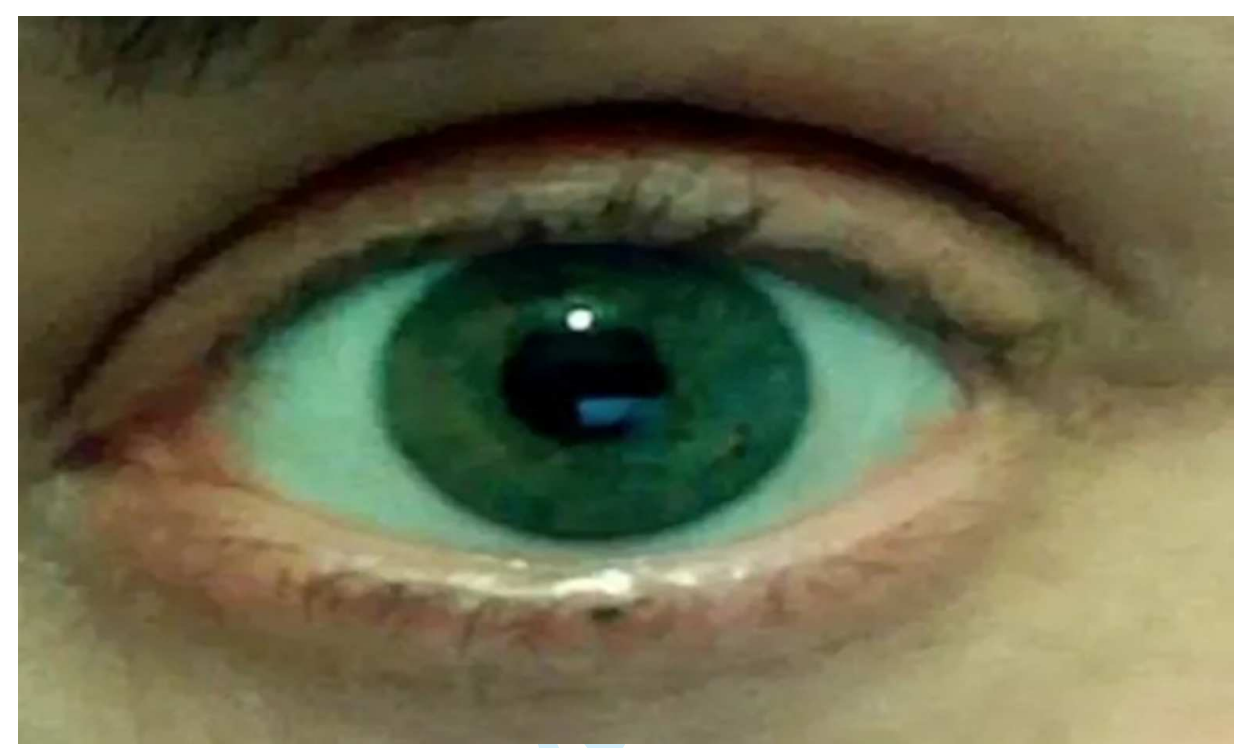

Image A. 'Sobriety'. Image taken by Jenny, a participant on supervision. 
Image B. 'Don't inject dope, because you'll be taken by the police'. Image taken by Chicks

Day employee Bora.

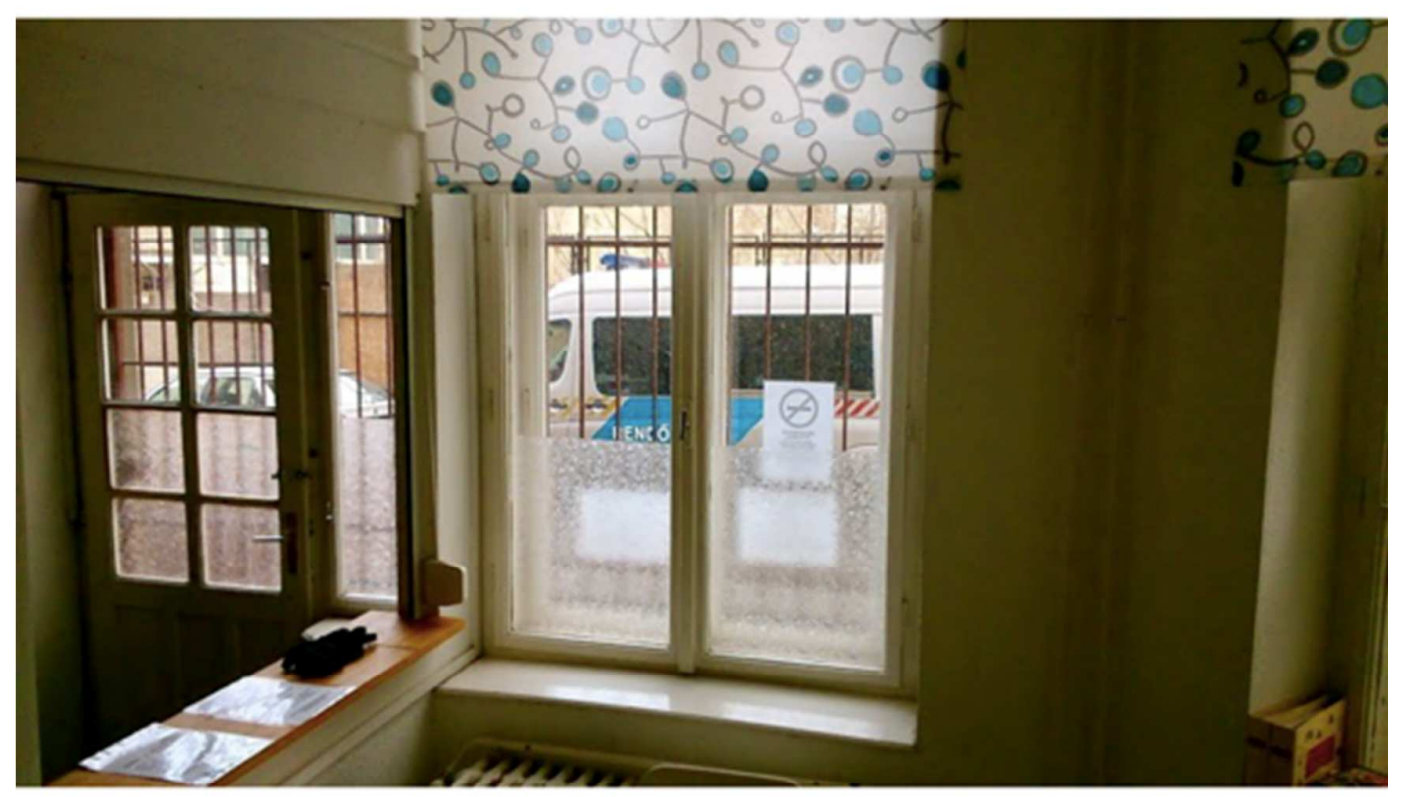

http://mc.manuscriptcentral.com/P\&S 


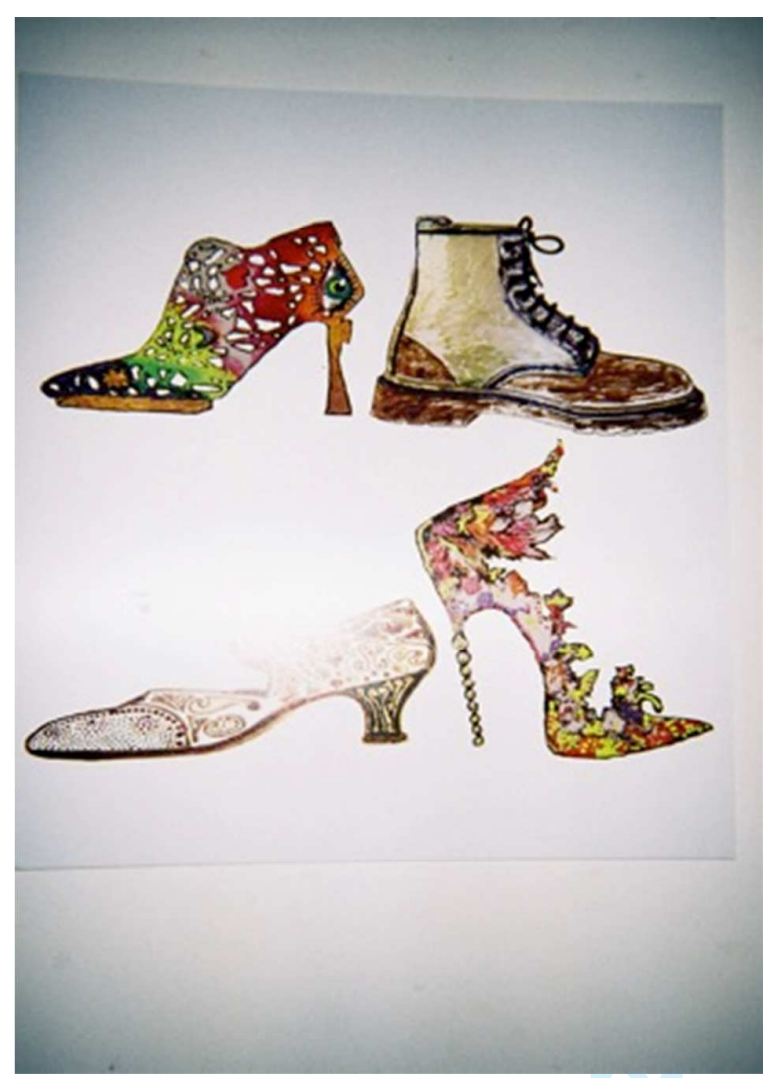

Image C. 'You never know a person until you walk a mile in their shoes'. Image taken by Betty, a participant on supervision. 


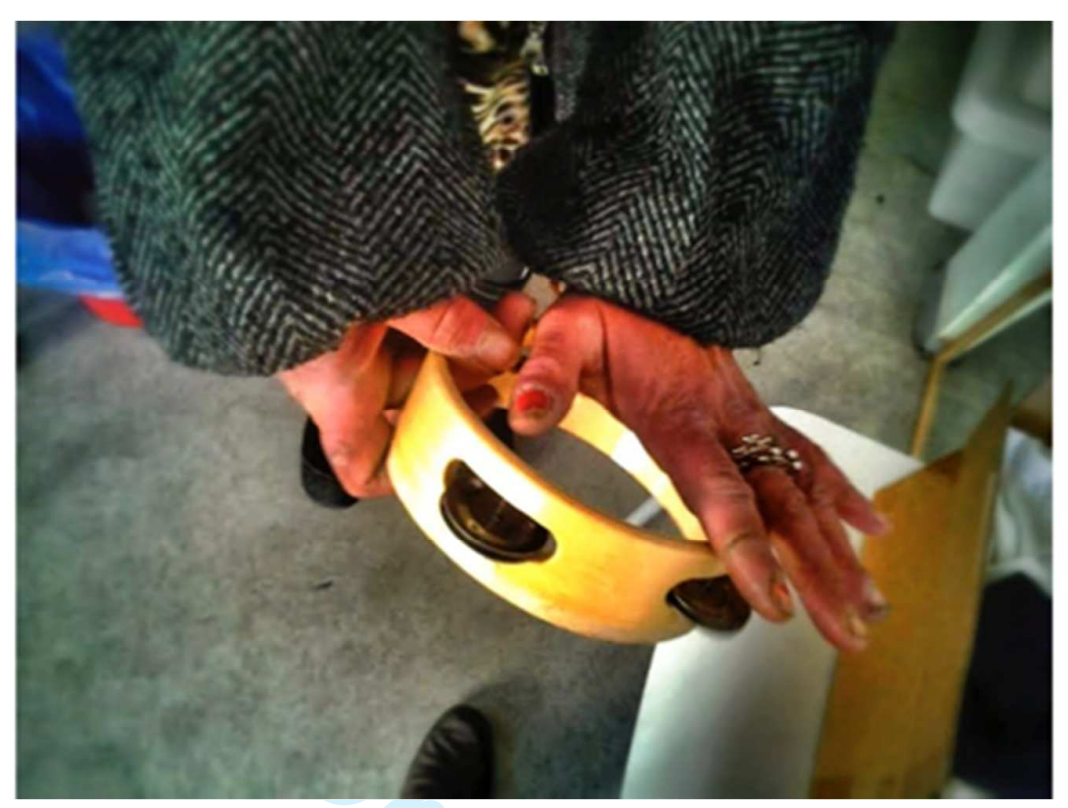

Image D. 'Trinkets' Image taken by Chicks Day employee Milla. 


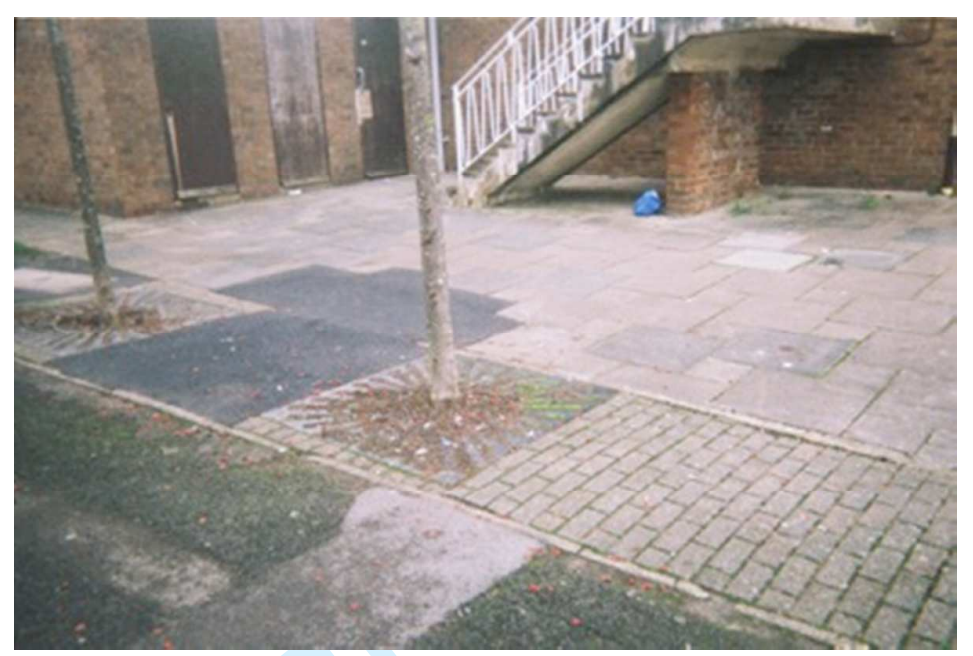

Image E. Untitled. Image taken by Rebecca, a participant of the women's centre. 


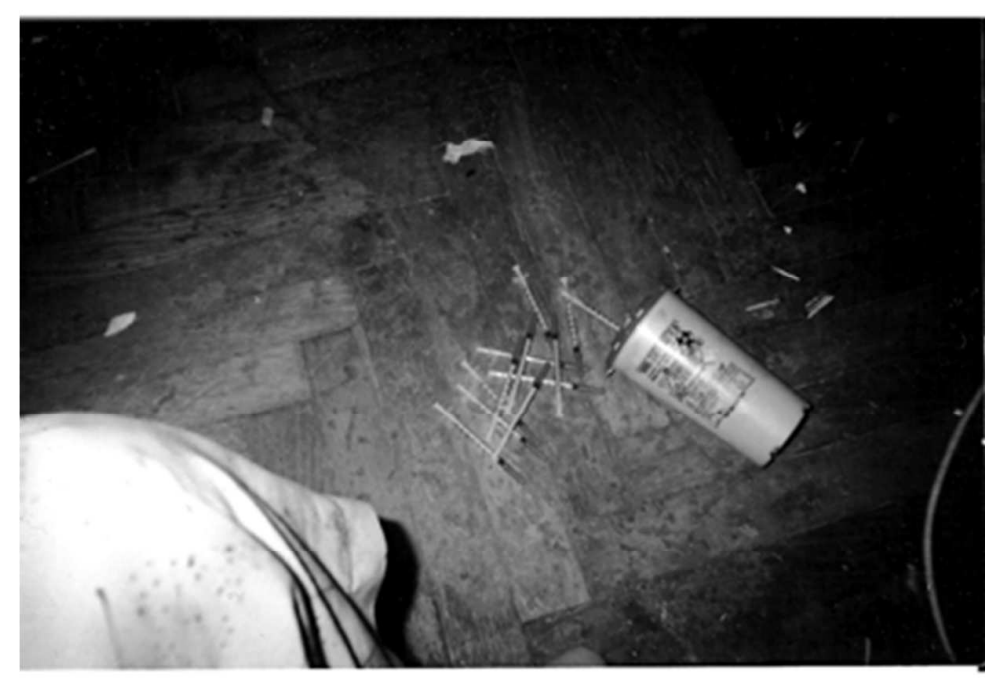

Image F. 'Watch out for others, use the badella!' Image taken by Chicks Day client Anikó. 


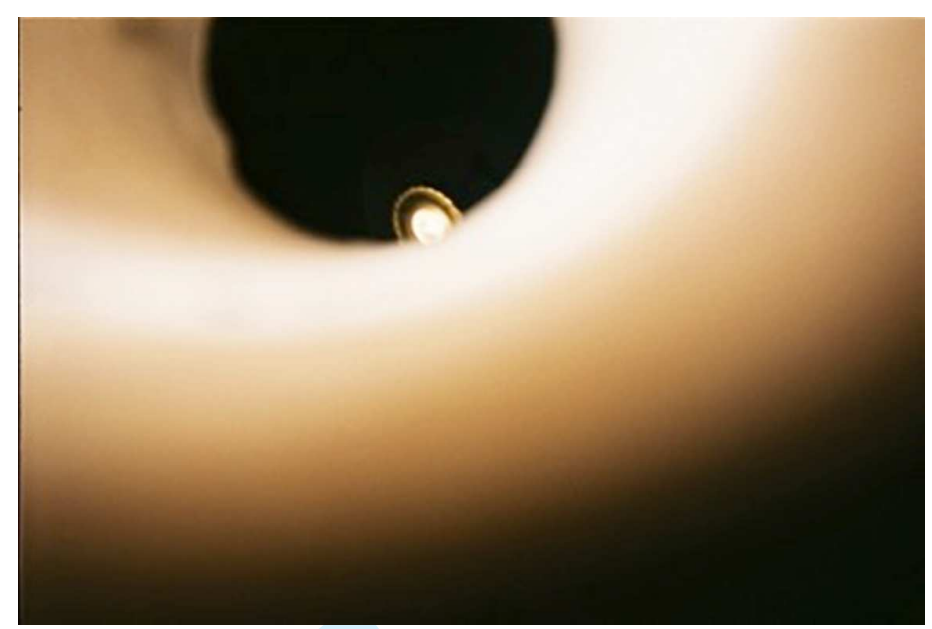

Image G. 'Light at the end of the tunnel'. Image taken by Sophie, a participant on supervision. 


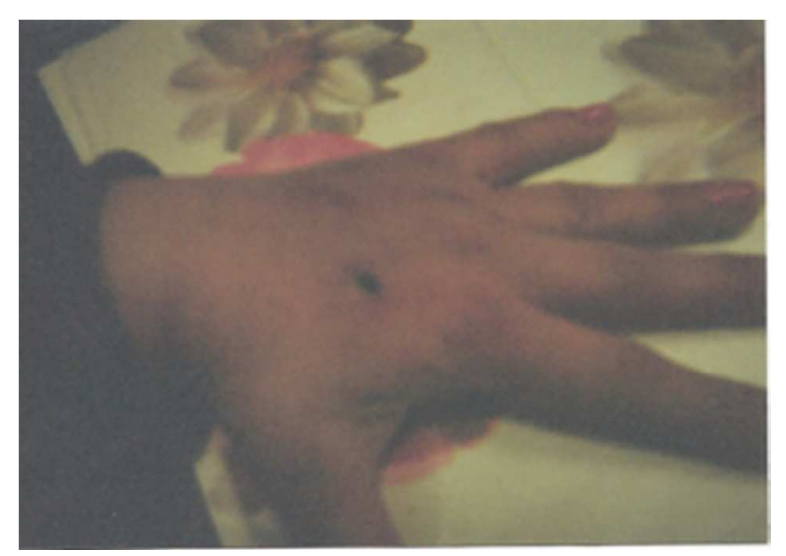

Image H. 'Teamwork, paying attention'. Image taken by Chicks Day client Csilla. 